\title{
Clinical outcomes of adjacent 1 segregation in a familial translocation $\mathrm{t}(8 ; 18)(\mathrm{p} 21.3 ; \mathrm{p} 11.23)$
}

\author{
Annette E Cockwell, Rowena S James, Isabella E Moore, Eli Hatchwell, \\ John A Crolla
}

\section{Wessex Regional Genetics Laboratory, Salisbury District Hospital, Salisbury, Wiltshire SP2 8BJ, UK A E Cockwell \\ R S James \\ J A Crolla}

\section{Department of \\ Histopathology, \\ Southampton General \\ Hospital, \\ Southampton SO16 \\ 6YD, UK \\ I E Moore}

Wessex Clinical

Genetics Service,

Princess Anne

Hospital,

Southampton SO16

5YA, UK

E Hatchwell

Correspondence to: Miss Cockwell.

Received 7 August 1995 Revised version accepted for publication 25 January 1996

\begin{abstract}
We report a reciprocal translocation $t(8$; 18)(p21.3;p11.23) in which both unbalanced products of adjacent 1 segregation were observed within a family. The proband was originally referred because of short stature and a webbed neck, but further investigations showed that she had mental retardation and a congenital heart defect, and had inherited an unbalanced form of the maternal translocation, 46, $X X, \operatorname{der}(8) t(8 ; 18)$ mat. The proband's sister spontaneously aborted an 11 week fetus with multiple major system malformations, which was found to have a $46, X Y$, $\operatorname{der}(18) t(8 ; 18)$ mat karyotype. The phenotypic findings of the affected subjects are discussed.
\end{abstract}

(f Med Genet 1996;33:515-517)

Key words: adjacent 1 segregation; chromosome 8; chromosome 18 .

Balanced reciprocal translocations occur with a frequency of approximately 1 in $658^{1}$ in the general population, and the breakpoints involved are nearly always unique, one notable exception being the $t(11 ; 22)$ translocation. ${ }^{2}$ However, it is often difficult to advise carrier couples on the a priori risk of giving birth to an abnormal child following malsegregation of a translocation. In an attempt to resolve this
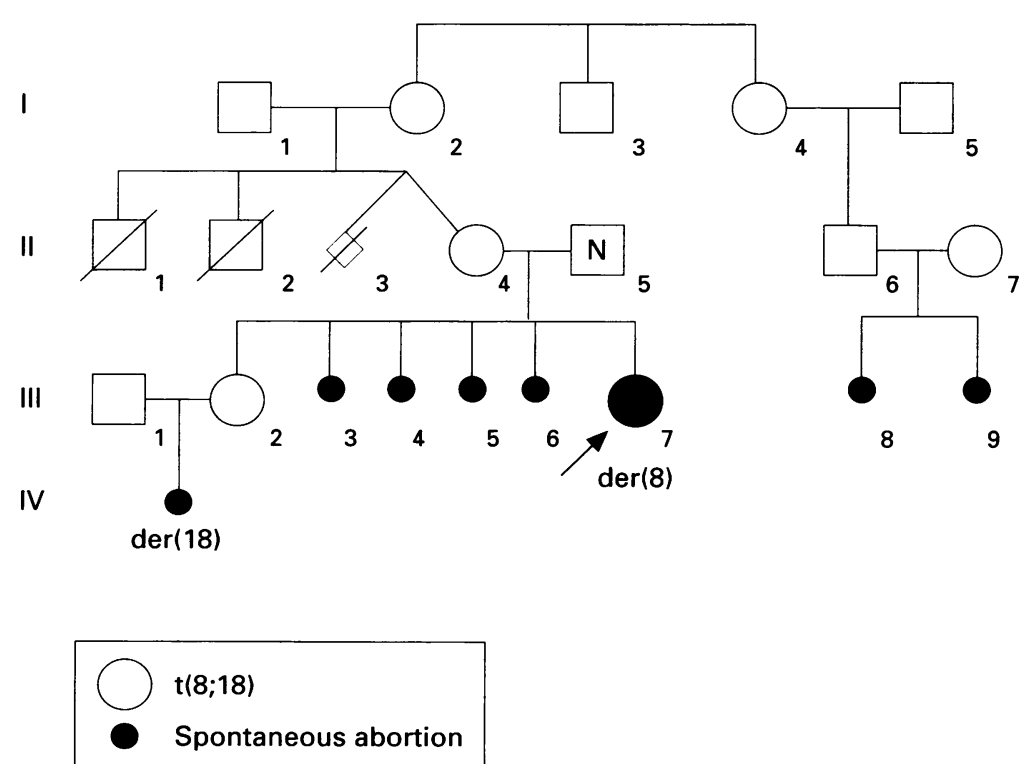

Figure 1 Pedigree of family with translocation $t(8 ; 18)(p 21.3 ; p 11.23) . I I \cdot 4, I I \cdot 5, I I I \cdot 2$, III $\cdot 7$, and IV 1 have been investigated cytogenetically. difficulty, Jalbert et $a l^{3}$ described a means by which the least unbalanced malsegregation of a translocation could be calculated, so that those gametes containing the least amount of duplication/deletion material, and therefore most likely to produce unbalanced and perhaps viable conceptuses, could be predicted. Nevertheless, empirical observations of the malsegregants of balanced translocations provide the most compelling evidence for the relationship between the amount and content of genetic imbalance and phenotypic effects. We report a family in which an $8 ; 18$ translocation segregated by both alternate and adjacent 1 modes. In the resulting unbalanced family members, the amount of deletion in one is equivalent to the extent of the duplication observed in the other. The proband with the derived 8 chromosome was not cytogenetically investigated until 15 years of age, whereas a fetus with the derived 18 spontaneously aborted at 11 weeks' gestation.

\section{Materials and methods}

CASE REPORT

The proband (fig 1, III -7) was first investigated cytogenetically aged 15 years, and was originally referred because of a webbed neck, short stature, and menorrhagia. A more detailed clinical history showed that at 8 weeks of age she had a correction of a tetralogy of Fallot with a transannular patch, and at that time was found to be microcephalic. At 13 years of age epileptiform seizures began and she was noted to be mentally retarded; a brain scan showed no structural abnormalities, although it was felt that the pattern of cortical sulcation might be accentuated. More recently she was referred to a cardiologist after an episode of retrosternal chest tightness, shortness of breath with pallor, and peripheral cyanosis brought on by climbing a hill near her home. On examination she was noted to be very obese and a chest $x$ ray showed cardiomegaly. She is currently being investigated for long term pulmonary regurgitation with a degree of right ventricular dysfunction.

Her phenotypically normal older sister (fig 1 , III 2 ) was counselled in early pregnancy that there was a 10 to $20 \%$ risk of her having a liveborn aneuploid offspring and she declined the offer of prenatal diagnosis. She had a spontaneous abortion (fig $1, \mathrm{IV} \cdot 1$ ) at 11 weeks' gestation. Necropsy showed a severely macerated fetus, crown-rump $20 \mathrm{~mm}$, crown-head $22 \mathrm{~mm}$, consistent with 9 weeks' gestation. The head was small in comparison to the length of 


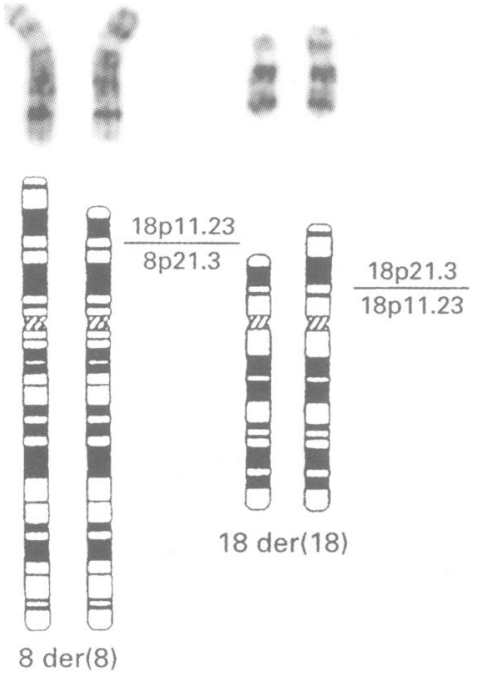

A

Figure 2 (A) Partial GTG banded karyotype of $t(8 ; 18)(p 21.3 ; p 11.23)$. Lines indicate breakpoints. (B) Pachytene configuration of $t(8 ; 18)$ (p21.3;p11.23). the body, the upper and lower limb buds were present, but only at the stage of finger and toe rays. Pigmented eyes were present, but there was no clear evidence of nasal and lip development. Although the posterior neuropore was closed, there was very delayed development of the cranial end of the CNS and of the thoracic organs, although the liver, adrenals, kidneys, and gut were clearly identified. Owing to some disruption of the fetus, probably artefactual, it was uncertain if there were any anterior thoracic or abdominal wall defects. A cystically dilated segment of umbilical cord was identified which contained only two vessels.

The proband's mother (fig 1, II-4) has also had four miscarriages (III-3-6) all between 6 and 12 weeks of gestation. She was one of twins, the other (II.3) apparently died during early pregnancy. Her two male sibs had also died. One (II-1) was born at 28 weeks' gestation and died at 24 hours, which at that time may have been because of prematurity, and the other brother (II.2) was born at term and died aged 18 months. The wife of her maternal cousin (II-6) has also had two early miscarriages.

\section{CYTOGENETIC STUDIES}

Peripheral blood lymphocytes were cultured from the nuclear family and the spontaneous abortion was examined from fibroblasts derived from villi. The metaphases were GTL banded using a modification of Seabright's method. ${ }^{4}$ Cell lines from the proband's mother (DD1481) and from the spontaneous abortion (DD1926) are available from ECACC, Porton Down, Salisbury, Wiltshire.

\section{MOLECULAR STUDIES}

To establish the presence of a deletion of distal chromosome 8p, DNA was extracted from peripheral blood lymphocytes from the proband
Results obtained using PCR amplification of microsatellite repeat sequences on chromosome 8 . The results at D8S264 and D8S201 show the maternal origin of the terminal deletion of $8 p$. Results at the more proximal D8S137 confirm the biparental inheritance of the chromosome 8 . All primer sequences have been published and are available on the Genome Data Base

\begin{tabular}{llll}
\hline Primers & AFM143xd8 & Mfd199 & c171b10 \\
Locus & D8S264 & D8S201 & D8S137 \\
Proband & $4,-$ & $3,-$ & 2,4 \\
Mother & 2,3 & 1,2 & 1,2 \\
Father & 1,4 & 3,3 & 3,4 \\
\hline
\end{tabular}

and both parents. Primers were prepared for PCR amplification of microsatellite repeat sequences on the short arm of chromosome 8 . Standard PCR conditions were used ${ }^{5}$ and PCR products were visualised on a $6 \%$ polyacrylamide DNA sequencing gel followed by autoradiography.

\section{Results}

CYTOGENETIC RESULTS

GTL banded metaphases from the proband (fig 1, III-7) showed what appeared to be a terminal deletion of one chromosome 8 at band p23.1. Her father was found to have a normal karyotype, but her mother carried an apparently balanced reciprocal translocation between $8 \mathrm{p} 21.3$ and $18 \mathrm{p} 11.23$, as shown in fig $2 \mathrm{~A}$. The proband's unbalanced karyotype therefore represents the inheritance of the derived chromosome 8 from her mother. The proband's sister (III-2) was also karyotyped and she was found to carry the same balanced translocation as her mother. The sister's subsequent spontaneous abortion (IV·1) was examined cytogenetically and showed an unbalanced male karyotype with the derived chromosome 18 inherited from its mother 46,XY,der(18)t(8; 18) (p21.3;p11.23)mat. No other family members were available for study.

\section{MOLECULAR RESULTS}

The results are shown in the table. The absence of a maternally inherited allele at D8S264 and D8S201 confirmed that a deletion of distal 8p in the proband was of maternal origin.

\section{Discussion}

Rarely are both products of an unbalanced segregation seen within a single pedigree. In our family the translocation has segregated both alternately, giving rise to balanced and presumably normal products, and by adjacent 1 segregation, the latter causing the unbalanced karyotype, which by using the method of Jalbert et $a l^{\beta}$ is predicted to be the mode of segregation giving rise to the least imbalance. The pachytene configuration for the $8 ; 18$ translocation is shown in fig $2 \mathrm{~B}$. The proband's karyotype is deleted for the segment $8 \mathrm{p} 21$ to 8 pter and, as expected, she has features associated with the $8 \mathrm{p}$ - syndrome, ${ }^{6}$ which include significant mental retardation, postnatal growth retardation, microcephaly, and congenital heart defects. More recently Hutchinson et al $l^{7}$ and Pettenati et $a l^{\beta}$ described five and three patients respectively 
and reviewed a further four cases in which they report a much milder phenotype when the breakpoint is at $8 \mathrm{p} 23.1$. However, these latter cases were terminal deletions in which no other chromosomes appeared to be involved, whereas our case may have been modified by the duplication of a portion of $18 \mathrm{p}$. A review of duplication $18 \mathrm{p}$ by Wolff et al ${ }^{9}$ found that only 14 cases have been reported previously; nine were detected because of family studies initiated by the diagnosis in another family member of monosomy or tetrasomy $18 \mathrm{p}$, that is, these unbalanced cases had been ascertained indirectly and may otherwise have remained undetected. Four cases had chromosome 18 as the sole rearranged chromosome and were not mentally impaired. However, five of the remaining 10 cases which had another chromosome involved in the imbalance were associated with mild mental retardation and non-specific dysmorphic features. Wolff et al ${ }^{9}$ concluded that duplication $18 \mathrm{p}$ does not appear to be associated with significant phenotypic abnormalities, so the phenotype of the proband in our case seems to be caused mainly by monosomy $8 \mathrm{p}$ with the congenital heart defect as the only life threatening feature.

In contrast, the other adjacent 1 product seen in the spontaneous abortion (IV-1) gave rise to a chromosome imbalance resulting in partial monosomy $18 \mathrm{p}$ and partial trisomy $8 \mathrm{p}$, and as could be predicted, a much more severe phenotype. The $18 \mathrm{p}-$ syndrome is a well characterised and relatively common autosomal deletion syndrome $\mathrm{e}^{10}$ in which holoprosencephaly, described in over $10 \%$ of reported cases, is probably the most significant congenital malformation. In addition, short stature, mental retardation, and dysmorphic facies are also observed. However, because of developmental delay observed in the fetus (IV.1), it is likely that the above abnormalities would have been more apparent if the fetus had survived for longer. Most of the 17 published cases of duplication $8 \mathrm{p}^{11-13}$ were born at term, unlike our spontaneous abortion (IV·1) which did not survive the first trimester. The majority of these 17 cases were unbalanced owing to mal- segregation of familial translocations, and all were severely mentally retarded, some with brain abnormalities including dilatation of the lateral ventricles or absence of the corpus callosum or both. The fetus in our case had very delayed development of the cranial end of the CNS even by 11 weeks gestation, but because of severe maceration, it is difficult to make further comparisons to those duplication $8 p$ patients that survived life in utero. Therefore, both chromosomal imbalances carried by the spontaneous abortion appeared to contribute towards the severe phenotype, in particular, brain abnormalities, which probably accounted for the fetus's early demise.

When the proband's family history is reviewed, it seems that the translocation may have been present in past generations. The proband's mother lost three sibs, one of which was her twin; and a cousin lost two offspring as spontaneous abortions. Unfortunately no other family members were available for study.

1 Jacobs PA, Browne C, Gregson NM, et al. Estimates of the frequency of chromosome abnormalities detectable in unselected newborns using moderate levels of banding. $\mathcal{f}$ Med Genet 1992;29:103-8.

2 Iselius L., Lindsten J, Aurias A, et al. The 11q;22q translocation: a collaborative study of 20 new cases and analysis of 110 families. Hum Genet 1983;64:343-55.

3 Jalbert P, Sele B, Jalbert H. Reciprocal translocations: a way to predict the mode of imbalanced segregation by

pachytene-diagram drawing. Hum Genet 1980;55:209-22. mosomes. Lancet 1971;ii:971-2.
moligue for human chro-

Huson TJ. Lancet 1971;ii:971-2.

Hudson TJ, Engelstein M, Lee MK, et al. Isolation and chromosomal assignment of 100 highly informative human simple sequence repeat polymorphisms. Genomics 1992; 13:622-9.

6 Dobyns WB, Dewald GW, Carlson RO, et al. Deficiency of chromosome 8 p21.1 $\rightarrow$ 8pter: case report and review of the literature. Am $\mathcal{F}$ Med Genet 1985;22:125-34.

7 Hutchinson R, Wilson $M$, Voullaire L. Distal $8 \mathrm{p}$ deletion (8p23.1 $\rightarrow$ 8pter): a common deletion? $\mathcal{F}$ Med Genet 1992;
29:407-11.

8 Pettanati MJ, Rao N, Johnson C, et al. Molecular cytogenetic analysis of a familial 8p23.1 deletion associated with minimal dysmorphic features, seizures, and mild mental retardation. Hum Genet 1992;89:602-6.

9 Wolff DJ, Raffel LJ, Ferré MM, et al. Prenatal ascertainment of an inherited $\operatorname{dup}(18 \mathrm{p})$ associated with an apparently normal phenotype. Am f Med Genet 1992;41:319-21.

10 Schinzel A. Catalogue of unbalanced chromosome aberrations in man. Berlin: de Gruyter, 1983:604-6.

11 MorenoFuenmayor $\mathrm{H}$, Meilinger KL, Rucknagel DL, et al. Duplication $8 \mathrm{p}$ syndrome: studies in a family with a reciprocal translocation between chromosomes 8 and 12 . Am $\mathcal{F}$ Med Genet 1980;7:361-8.

12 Clark CE, Telfer MA, Cowell HR. A case of partial trisomy $8 \mathrm{p}$ resulting from a maternal balanced translocation. $\mathrm{Am}$ f Med Genet 1980;7:21-5.

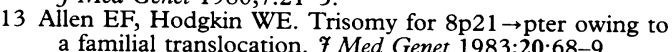

